\title{
NEW YORK RHEUMATISM ASSOCIATION
}

At the Annual Meeting of the New York Rheumatism Association held on April 12, 1955, at Cornell University, the following officers were elected:
President:
Vice-President:
Dr. William H. Kammerer
Secretary-Treasurer:
Executive Committee:
Dr. Jack R. Dordick
Dr. Bernard Rogoff
Dr. Morris Ziff
Dr. Rubin Klein
Dr. Charles M. Plotz

The following papers were given at the clinical meeting:

Use of the Hypospray for Intra-Articular Injection. By Morris Ziff, Vincent Contreras, and Frank ScHmid, Study Group on Rheumatic Diseases, Department of Medicine, New York University College of Medicine.

A preliminary report on the use of the hypospray jet injector for intra-articular injection is presented. The injector forces a fine jet of the material through the skin and subcutaneous tissues, and now, we believe, through the articular capsule.

Various joints of an unembalmed cadaver were initially injected by the hypospray, using trypan blue. On dissection, the dye was found to be deposited in the joint cavity and to some extent in the periarticular tissues. When diodrast was injected into the joints of patients the periarticular localization of the material was evident.

In other studies with the hypospray, 34.5 and 59.6 per cent. of trypan blue in one instance, and 1.2 and 13.6 per cent. of hydrocortisone in another instance, could be recovered from the knee and elbow, respectively.

Clinical studies were limited to small joints of the hands and wrists of 25 patients with rheumatoid arthritis. One hundred injections were made, $15 \mathrm{mg}$. hydrocortisone acetate in $0.6 \mathrm{ml}$. using the smaller joints, and $25 \mathrm{mg}$. in $1 \mathrm{ml}$. for the wrist and larger joints. After initial trials with the conventional instrument, a special instrument 18 per cent. more powerful was used; this latter gave major improvement in fifteen of eighteen proximal interphalangeal joints, in five of six metacarpophalangeal joints, and in six of eleven wrist joints.

No serious complications have resulted. Mild pain of seconds to minutes is occasionally reported by some patients, especially with small joints. The hypospray is almost uniformly preferred to needle injection.

Effect of Salicylate in Varying Dosage on Urinary Urate Excretion in Gouty Subjects. By A. B. Gutman and T. F. YÜ, Department of Medicine, Mount Sinai Hospital, and Department of Medicine, Columbia University College of Physicians and Surgeons.

Salicylates paradoxically cause urate retention in small doses, uricosuria in large doses. Thus the mean effect of $2 \mathrm{~g}$. aspirin/day on the 24-hr urinary urate excretion and serum urate levels was $-14 \cdot 4$ and $+7 \cdot 5$ per cent. respectively (in seven gouty subjects); whereas, with $5 \cdot 2$ g. aspirin/day it was +37.2 and -23.9 per cent. respectively (in 15 gouty subjects) when given alone, and +85.7 and -40.4 per cent. with concurrent sodium $\propto$ bicarbonate $5 \mathrm{~g}$./day, which is itself not uricosuric. §ै Intermediate doses of aspirin, $3 \mathrm{~g}$./day, had little effect on urine and serum urate in six or nine gouty subjects.

Renal clearance studies showed depression of net $\overrightarrow{\vec{\omega}}$ urate clearance (C urate) when little salicylate was $\omega_{\text {o }}$ excreted in the urine (low UV-free salicylate) and marked enhancement when UV-free salicylate was high. A ? curve relating $\mathrm{C}$ urate to UV-free salicylate was dis- $\vec{A}$ continuous, implying at least two distinct urate tubular $\rightarrow$ transport mechanisms; one for tubular urate reabsorption, $\vec{A}$ suppressed by high UV-free salicylate, the other (?tubular $\stackrel{\vec{\perp}}{\vec{A}}$ urate excretion) suppressed by low UV-free salicylate. 옥 Sodium bicarbonate increases the UV-free salicylate, and hence suppresses tubular reabsorption of urate as the 0 urinary $p \mathbf{H}$ rises.

Observations concerning the Mode of Action of the Antirheumatic Phenolic Acids. By JosePh C. Turner, $\stackrel{\mathbb{D}}{-}$ Columbia University College of Physicians and $\vec{\theta}$ Surgeons.

After intravenous injection gentisate is excreted rapidf and soon disappears from most organs except the skeleft connective tissues, in which it remains for a considerable time. The in vitro binding of gentisate by various proteins demonstrated an attachment to serum albumin in the molar ratios that characterize other cations of similar molecular size. Oxidation products of gentisate (gentisoquinone) can be separated electrophoretically into at least four distinct components. Some of these appear to be firmly bound not only by serum albumin but also by insoluble connective tissue proteins, e.g. collagen.

It is suggested that the mode of action of the antirheumatic phenols may involve their oxidation in vivo 음 to quinones which interact with connective tissue, i.e. that there is an analogy with the metabolism of homogentisic acid in the alkaptonuric.

Butazolidin. By William B. Rawls, Polyclinic Hospital.

Two hundred patients were given Butazolidin for $\frac{7}{3}$ periods varying from one to 24 months. A total of 2,500 blood counts were done; one every week for the $N$ first 3 weeks and every 2 weeks thereafter. Where a reduction of the total white cells or polymorphonuclears $N$ occurred, blood counts were continued each week. The స్ట maximum dosage used was $400 \mathrm{mg}$. per day. It was $\sigma$ necessary to reduce the dose or to omit the Butazolidin in many instances, and in most cases the count returned $\stackrel{\varrho}{=}$ to normal in a short time, but when the medication was $\stackrel{\Phi}{\infty}$ again given, a reduction of the total white count or ? polymorphonuclears would again occur. Many patients 
would tolerate only 100 or $200 \mathrm{mg}$. daily and some would not tolerate any. One patient developed a true agranulocytosis although receiving only $300 \mathrm{mg}$. daily for 3 weeks. Another patient with agranulocytosis came under my care, who had been given $600 \mathrm{mg}$. of Butazolidin daily. Two patients had mild gastric bleeding: one had a previous history of gastric ulcer, but $x$ rays showed this to be completely healed, and there was no history of ulcer in the second. There was sodium retention in some but this was not a troublesome factor. Except for the effect upon the blood count, total white cells, and polymorphonuclear count, the toxicity was not particularly troublesome.

Treatment of Various Rheumatic Conditions with Metacortandracin. By WILliam H. KAMMerer and Russell L. Cecil, New York Hospital.

Meticorten, or prednisone* is a more potent antirheumatic agent than either cortisone or hydrocortisone.

To date, major side-effects, in a group of 56 patients with rheumatoid arthritis and ten patients with osteoarthritis, have been limited to one patient with peptic ulcer and one with thrombophlebitis. These may or may not have been drug-induced. This report deals only with short-term results. Whether improvement will be maintained under treatment, remains to be seen.

Untoward Reactions to Metacortandracin. By ChARLES M. Plotz, Mount Sinai Hospital Musculo-skeletal Team.

Metacortandracin has now been widely used in the management of rheumatoid arthritis and related disorders and in allergic conditions. The author has used this new synthetic hormone in thirty such cases with the usual good result in most instances.

Three patients (10 per cent.) of the series developed untoward reactions while on the hormone:

(1) A 61-year-old male developed an area of activity surrounding an old pulmonary cavitation, probably tuberculous.

(2) A 52-year-old female with no previous gastric complaints developed severe abdominal pain of the type associated with active peptic ulcer, terminated only by elimination of the hormone.

(3) A 50-year-old female with mild psoriasis and severe rheumatoid arthritis developed severe generalized psoriasis during treatment.

It is recognized that this high incidence of untoward reactions may be coincidental, particularly in view of the absence of such reactions from other reports. It is further recognized that metacortandracin is of unquestioned value in the management of responsive disorders. This report is tendered to serve as a warning that the hormone is a potent agent capable of producing severe side-reactions and should therefore be used with care.

Preliminary Clinical Trials with Metacortandracin. By J. R. DORDICK, Beth Israel Hospital.

Twelve patients with active rheumatoid arthritis previously treated with cortisone, corticotropin, or hydro-

* The generic term recently assigned to Meticorten or Metacortandracin by the Council on Pharmacy of the American Medical Association. cortisone were directly transferred to $\triangle^{\mathbf{1}}$-dehydrocortisone (prednisone; Meticorten). Previous results in these patients had been unsatisfactory, or accompanied by undesirable side-effects, or both. During 3 months of observation, it was found that the new steroid (Meticorten) produced a rapid, effective, and consistent antiinflammatory response on oral administration, exhibiting subjective improvement, as well as objective benefits, reduction in temperature, and sedimentation rate.

Meticorten is four to five times more potent than cortisone or hydrocortisone. Serial studies of the urine or serum electrolytes demonstrated no significant sodium retention or potassium depletion, when therapeutic doses were administered, on a fixed sodium dietary intake. Salt-loading experiments in four cases substantiated this.

The pattern of relapse or recrudescence after abrupt or total withdrawal of Meticorten was similar to that seen after sudden discontinuance of cortisone.

Although cortisone, hydrocortisone, and Meticorten are qualitatively identical in suppressing active rheumatoid arthritis, Meticorten is quantitatively superior and free from serious metabolic, water, or electrolyte disturbances. This is a short-term report, and it is emphasized that the suppressive doses never exceeded $30 \mathrm{mg}$. per day. The average maintenance dose was 10 to $15 \mathrm{mg}$. daily.

Treatment of Scleroderma, Sclerodactylia, and Calcinosis by Chelation. By Rubin KLeIN and SAMUel B. HARRIS, Greenpoint Hospital.

A 45-year-old female had been ill for 11 years with collagen disease. During the last 5 years she had definite evidence of scleroderma, sclerodactylia, and calcinosis. This was confirmed by biopsy, $x$ rays, and physical examination. The patient was treated with the sodium salt of ethylene diamine tetra acetic acid 20 per cent. (EDTA), $3 \mathrm{~g}$. being added to $500 \mathrm{ml} .5$ per cent. dextrose in water and given by slow intravenous drip. The infusion usually took $3 \mathrm{hrs}$; the treatment was continued on alternate weeks for 8 weeks, and the patient received a total of $84 \mathrm{~g}$. Complete blood, urine, $x$ ray, and biopsy studies were made before, during, and after treatment. The blood calcium fluctuated slightly, and the output of calcium in the urine increased up to 300 per cent. After 12 weeks there was about a 90 per cent. loss of calcium in the left elbow and about 30 per cent. in the fingers of the left hand. There were no changes in the fingers of the right hand. Biopsies of the skin showed a definite improvement in the scleroderma. The patients' daily activity and physical condition also improved. There was no evidence of toxicity during treatment or on follow-up 3 months later.

Severe Rheumatoid Arthritis during Four Years of Induced Hyperadrenalism. By DAvid S. Howell, Columbia University College of Physicians and Surgeons (see p. 429).

Natural History of Marie-Strümpell Arthritis. By Baruch S. Blumberg, Columbia University College of Physicians and Surgeons (see p. 432). 